\title{
ISPA cage-like particle adjuvant enhances protection induced by A/Arg/2001 Foot and Mouth Disease Virus-Like Particles
}

\author{
Juan Esteban Bidart ${ }^{1}$, Ana Mignaqui ${ }^{1}$, Claudia Kornuta ${ }^{1}$, Giuliana Lupi ${ }^{2}$, Mariela \\ Gamella $^{1}$, Ivana Soria ${ }^{1}$, Roxana Galarza ${ }^{1}$, Sabrina Cardillo ${ }^{3}$, Cecilia Langellotti ${ }^{1}$, Valeria \\ Quattrocchi $^{1}$, Yves Durocher ${ }^{4}$, Andrés Wigdorovitz ${ }^{1}$, Ivan Marcipar ${ }^{2}$, and Patricia \\ Zamorano $^{1}$ \\ ${ }^{1}$ Instituto Nacional de Tecnologia Agropecuaria \\ ${ }^{2}$ CONICET \\ ${ }^{3}$ Biogenesis Bago SA \\ ${ }^{4}$ Canadian Institutes of Health Research
}

July 16, 2020

\begin{abstract}
Foot-and-Mouth Disease Virus (FMDV) causes an acute disease with important economy losses worldwide. Currently available vaccines are based on inactivated FMDV and oil-adjuvants. The use of Virus-Like Particles (VLPs) for subunit vaccines has been reported to be promising since it avoids the biological hazard of using virus in vaccine production while conserving conformational viral epitopes. However, a more efficient and cost-effective adjuvant than those currently used is needed. Immunostimulant-Particle Adjuvant (ISPA) is an Immune Stimulating Complex (ISCOM) - type adjuvant formulated with dipalmitoyl-phosphatidylcholine, cholesterol, stearylamine, alpha tocopherol and QuilA. In the present work, we have evaluated the immune response against FMDV using VLPs and ISPA as adjuvant. VLPs (serotype A/Arg/01) were obtained by transient gene expression in mammalian cell cultures, and a previously developed murine model, able to predict the ability of a vaccine to induce protection in cattle, was used for vaccination experiments in a first approach. The VLPs-ISPA vaccine induced protection in mice against challenge and elicited a specific antibody response in sera. In a second approach, the VLPs-ISPA vaccine was tested in calves. Interestingly one vaccine dose was enough to induce total $\alpha$-FMDV antibodies, as measured by ELISA, as well as neutralizing Abs. Antibody titers reached an Expected Percentage of Protection higher than 90\%. The EPP index calculates the probability that livestock will be protected against a challenge of 10.000 bovine infectious doses after vaccination. Moreover, IFN- $\gamma$ levels secreted in vitro by mononuclear cells of VLP-ISPA vaccinated animals were significantly higher $(\mathrm{p}<0.05)$ than in the non-adjuvanted VLPs group. Overall, the results demonstrate that VLPs and ISPA are a promising combination for the development of a novel FMD vaccine, since no infectious FMDV is used and a protective immune response can be induced in calves, comparable to that achieved with the commercial FMDV vaccine.
\end{abstract}

ISPA cage-like particle adjuvant enhances protection induced by A/Arg/2001 Foot and Mouth Disease VirusLike Particles

Bidart, $\mathrm{J}^{1,2}$, Mignaqui, $\mathrm{A}^{12}$, Kornuta, $\mathrm{C}^{1,2}$, Lupi, $\mathrm{G}^{2,3}$, Gammella, $\mathrm{M}^{1}$, Soria, $\mathrm{I}^{1}$, Galarza, $\mathrm{R}^{1}$, Cardillo, $\mathrm{S}^{4}$, Langellotti, $\mathrm{C}^{1,2}$; Quattrocchi, $\mathrm{V}^{1}$; Durocher, $\mathrm{Y}^{5}$, Wigdorovitz, $\mathrm{A}^{1}$, Marcipar, $\mathrm{I}^{2,3}$, Zamorano, $\mathrm{P}^{1,2,6^{*}}$

${ }^{1}$ Instituto Nacional de Tecnologia Agropecuaria, Buenos Aires, Buenos Aires, AR

${ }^{2}$ CONICET Buenos Aires, Buenos Aires, AR

${ }^{3}$ Universidad Nacional del Litoral Facultad de Bioquímica y Ciencias Biológicas, Santa Fe, AR 
${ }^{4}$ Biogenesis Bago SA, Buenos Aires, AR

${ }^{5}$ Canadian Institutes of Health Research, Ottawa, ON, CAN

${ }^{6}$ Universidad del Salvador, Buenos Aires, AR

* Corresponding author: Dr. Patricia Zamoranozamorano.patricia@inta.gob.ar

Short Running title: FMDV VLPs and ISPA enhance protection against FMD

Keywords: FMDV 1 , Virus-Like Particles 2 , protection $_{3}, \mathrm{ISPA}_{4}$, vaccine ${ }_{5}$, adjuvant $_{6}$,

Abstract

Foot and Mouth Disease Virus (FMDV) causes an acute disease with important economy losses worldwide. Currently available vaccines are based on inactivated FMDV and oil-adjuvants. The use of Virus-Like Particles (VLPs) for subunit vaccines has been reported to be promising since it avoids the biological hazard of using virus in vaccine production while conserving conformational viral epitopes. However, a more efficient and cost-effective adjuvant than those currently used is needed. Immunostimulant-Particle Adjuvant (ISPA) is an Immune Stimulating Complex (ISCOM) - type adjuvant formulated with dipalmitoyl-phosphatidylcholine, cholesterol, stearylamine, alpha tocopherol and QuilA. In the present work, we have evaluated the immune response against FMDV using VLPs and ISPA as adjuvant. VLPs (serotype A/Arg/01) were obtained by transient gene expression in mammalian cell cultures, and a previously developed murine model, able to predict the ability of a vaccine to induce protection in cattle, was used for vaccination experiments in a first approach. The VLPs-ISPA vaccine induced protection in mice against challenge and elicited a specific antibody response in sera. In a second approach, the VLPs-ISPA vaccine was tested in calves. Interestingly one vaccine dose was enough to induce total $\alpha$-FMDV antibodies, as measured by ELISA, as well as neutralizing Abs. Antibody titers reached an Expected Percentage of Protection higher than 90\%. The EPP index calculates the probability that livestock will be protected against a challenge of 10.000 bovine infectious doses after vaccination. Moreover, IFN- $\gamma$ levels secreted in vitro by mononuclear cells of VLP-ISPA vaccinated animals were significantly higher $(\mathrm{p}<0.05)$ than in the non-adjuvanted VLPs group. Overall, the results demonstrate that VLPs and ISPA are a promising combination for the development of a novel FMD vaccine, since no infectious FMDV is used and a protective immune response can be induced in calves, comparable to that achieved with the commercial FMDV vaccine.

\section{Introduction}

Foot-and-Mouth Disease (FMD) is a highly contagious viral infection of cloven-hoofed animals. FMD is endemic in many parts of the world and continues to pose a major threat to livestock industries. Its presence in a country results in severe restrictions to international trade and an outbreak in FMD-free countries causes billionaire losses (OIE - World Organisation for Animal Health Act $N^{\circ} 22,2018$; Thompson et al., 2002). Prevention and eradication of the disease requires sustained efforts at a significant cost. Vaccination is a major strategy in developing countries to control FMD (Parida, 2009).

The etiological agent is Foot-and-Mouth Disease Virus (FMDV), a member of the Aphthovirus genus within the Picornaviridae family. FMDV has a single-stranded, positive sense RNA genome that is enclosed within a protein shell comprised of 60 copies of 4 structural proteins, VP1, VP2, VP3 and VP4. VP1-VP3 are surface exposed on the virus particles,, whereas VP4 is internal (Acharya et al., 1989). The capsid proteins facilitate virus entry and delivery of the genome into the cytoplasm of the cell where translation and replication of the viral RNA takes place, and new virus particles are formed (Belsham, 2005; Jackson et al., 2000; Monaghan et al., 2005). The immune system of virus-infected animals produces neutralizing Abs against the surface-exposed capsid proteins, which is a key requirement for protection (Doel, 2003).

Seven FMDV serotypes (A, O, C, SAT1, SAT2, SAT3 and ASIA1) and several subtypes within each serotype have been described. Viral infection or vaccination with one serotype does not confer protection against other 
serotypes (Mattion et al., 2004). Thus, an update of the antigenic composition of the vaccine is required when new field strains appear. The vaccine currently used consists on chemically inactivated virus. To produce this vaccine, suspension-growing baby hamster kidney-21 (BHK-21) cells are infected with virus and binary ethyleneimine is used for the inactivation process (Doel, 2003; Grubman \& Baxt, 2004; OIE World Organisation for Animal Health, 2012). There are disadvantages with the use of this type of vaccine, including the need for high biosafety production facilities, the risk of incomplete inactivation of the virus, the need of an strict purification process that guaranties differentiation of infected from vaccinated animals and the fact that some serotypes and subtypes have problems to grow in cell cultures (Grubman, 2005; Rodriguez \& Grubman, 2009). Thus, the development of new vaccines is desirable.

Recombinant VLPs may represent a good alternative to the conventional FMD vaccine since they are noninfectious and can be produced without the need of high containment facilities and may also be modified to enhance their stability (Caridi et al., 2015; Ellard et al., 1999; Kotecha et al., 2015; Mateo et al., 2008; Porta et al., 2013; Rincón et al., 2014). The use of suspension-growing mammalian cells, economic and efficient transfection reagents and optimized expression vectors has allowed transient gene expression (TGE) to become a simple, scalable and powerful technology to generate large amounts of recombinant VLPs within a short time period (Baldi et al., 2007; Mignaqui et al., 2013; Pham et al., 2006).

Although some reports have demonstrated the efficacy of FMD vaccines based on VLPs (Li et al., 2012; Porta et al., 2013; Xiao et al., 2016), a lower performance of a VLP based vaccine can be expected when compared with a traditional vaccine due to the lack of viral RNA, a well-known activator of the innate immune response (Medina et al., 2018). Moreover, vaccines based on these empty capsid particles may still be expected to suffer from some of the same shortcomings, (e.g. in terms of duration of immunity)(Gullberg et al., 2016). The use of novel adjuvants can be a promising tool to improve the performance of these vaccines.

In the present work, FMDV serotype A/Argentina/2001 VLPs were produced by transient gene expression in serum-free suspension-growing mammalian cells, using polyethylenimine (PEI) as transfection reagent (Mignaqui et al., 2013). Serotype A/Argentina/2001, isolated during an outbreak of FMD in Argentina in 2000 (Mattion et al., 2004), was used in the present study as proof of concept.

Our laboratory has ample experience in a murine model that proved useful to evaluate the potency of FMDV vaccines (Batista et al., 2010; Bidart et al., 2020; Gnazzo et al., 2020; C Langellotti et al., 2012; Cecilia Langellotti et al., 2015; V Quattrocchi et al., 2011, 2013; Valeria Quattrocchi et al., 2005; Romanutti et al., 2013; Zamorano et al., 2010). In this model, there is a correlation with the humoral and protective immune responses against infective FMDV that take place in cattle (Gnazzo et al., 2020).

Vaccine adjuvants improve the immune response elicited against antigens, direct the immune response to a particular profile, increase the number of responding individuals, reduce the amount of vaccine doses and/or allow to reach homogenous immune responses (Mohan et al., 2013). It is of great importance to find new adjuvants that allow reducing the amount of virus or antigens in vaccines and induce Th1/Th2 responses. Other desirable characteristics include low cost and stability. It has been reported that Immune Stimulating Complexes (ISCOMs) are capable of developing a Th1/Th2 balanced immune response, in addition to increasing cytotoxic responses (Bertona et al., 2017; Maraskovsky et al., 2009; Singh, 2006; Sun et al., 2009). ISCOMs are spherical particles of approximately $40 \mathrm{~nm}$ in diameter, composed of phospholipids, cholesterol and saponin, which can retain the antigen through hydrophobic interactions (Morein et al., 1984; Singh, 2006). They have been applied to the development of several registered vaccines for veterinary applications (Sun et al., 2009). Recently, the Immunostimulating Particle Adjuvant or ISPA, an empty cage-like particle formulation similar to ISCOMATRIX, was described. It contains dipalmitoyl-phosphatidylcholine (DPPC), cholesterol (CHO), stearylamine (STEA), alpha-tocopherol (TOCO) and Quil A saponin (Bertona et al., 2017; Bidart et al., 2020; Prochetto et al., 2017). This adjuvant was shown to surpass conventional ones by improving humoral and cellular CD4+ / CD8+ responses (Bertona et al., 2017). Recently, we reported that an inactivated FMDV serotype A vaccine adjuvanted with ISPA was capable of inducing protection against challenge in a murine model and of improving the specific immune responses against FMDV in cattle (Bidart et al., 2020). 
In this report, we demonstrate for first time the effect of ISPA as adjuvant for a subunit vaccine using VLPs from FMDV both in a murine model and in cattle.

\section{Materials and Methods}

\subsection{Animals}

All experiments involving the use of animals were carried out according to INTA Ethics Manual "Guide for the use and care of experimental animals", under protocol Number: 26/2016.

Male BALB/c mice, 8-12 weeks old from the animal facilities of the School of Veterinary Sciences, University of Buenos Aires, Argentina, were used.

FMDV-seronegative calves as determined by enzyme-linked immunosorbent assay (ELISA), according to Hamblin et al. (1986), of approximately 8-10 months old, were used in the experiment (Hamblin et al., 1986).

\subsection{Virus-like particles (VLPs)}

Recombinant VLPs were obtained as previously reported (Mignaqui et al., 2013). Briefly, suspension-growing 293-6E cells were grown in serum-free F17 medium (Gibco) at 37degC with $5 \% \mathrm{CO}_{2}$ and agitation at $120 \mathrm{rpm}$. Cells were transiently transfected with pTT5-P12A3C plasmid encoding for FMDV Serotype A/Arg/2001 VLPs using polyethylenimine (LPEI-MAX) (Polysciences, Warrington, PA, USA). Cells were harvested 48 $\mathrm{h}$ post transfection, centrifuged at $4000 \mathrm{~g}$ and the pellet was resuspended in Tris- $\mathrm{HCl}, \mathrm{pH} 8$, and subjected to three freeze-thaw cycles at $-80 \mathrm{oC} / 25 \mathrm{oC}$. Finally, the lysate was clarified by centrifugation and VLPs were quantified by ELISA, as previously reported (Mignaqui et al., 2013). Briefly, a polyclonal anti-FMDV serum raised in rabbit was used for coating microtiter plates (Maxisorp). After washing steps, plates were blocked for $30 \mathrm{~min}$ at $37 \mathrm{degC}$ with $5 \%$ normal equine serum in PBS/0.1\% Tween-20. VLPs samples were added to the wells and incubated at $37 \mathrm{degC}$ for $1 \mathrm{~h}$. A standard curve was generated using serial dilutions of a quantified aliquot of inactivated FMDV. Plates were then incubated for $1 \mathrm{~h}$ with a polyclonal antiFMDV serum raised in guinea pig, followed by horseradish peroxidase-conjugated goat anti-guinea pig IgG (KPL). Then, tetramethylbenzidine was used as substrate and the absorbance at $450 \mathrm{~nm}$ was recorded in a microplate reader (Thermo Scientifics MultiskanFC).

\subsection{Virus}

FMDV serotype A/Arg/2001 (A2001) inactivated (iFMDV) with binary ethyleneimine (provided by Biogenesis Bago, Buenos Aires) and purified by sucrose gradient was used as a positive control for protein characterization assays, to formulate experimental vaccines, in ELISA and in cellular assays. Infectious virus, obtained from vesicles of experimentally infected cattle (provided by the Argentine National Service of Animal Health, SENASA) with one or two passages in BHK-21 cells, was used for viral challenge. All experiments involving infectious virus were performed in the INTA BSL-4 OIE facilities.

\subsection{Selection of VLPs dose for vaccine formulation}

To select the VLPs vaccine dose, dilutions of VLPs in PBS containing: 8, 4, 2, 1, 0.5, 0.3, 0.15 or $0 \mu \mathrm{g}$ in a final volume of $0.1 \mathrm{ml}$ were prepared. Groups of mice $(\mathrm{n}=5)$ were subcutaneously ( $\mathrm{sc}$ ) inoculated at 0 and $21 \mathrm{dpv}$ with these formulations. Animals were challenged with an ip injection of $10^{2.5} \mathrm{TCID}_{50} / \mathrm{ml}$ infectious FMDV, A2001 serotype, at 36 days post vaccination (dpv). Twenty-four $\mathrm{h}$ later, viremia was evaluated as described in Bidart et al (2020) (Bidart et al., 2020). Briefly, heparinized blood withdrawn at $24 \mathrm{~h}$ post infection was spread onto BHK-21 cell monolayers grown in 48-well plates and incubated at $37^{*} \mathrm{C}$ in a $5 \%$ $\mathrm{CO}_{2}$ atmosphere. Then, cell monolayers were washed twice with sterile PBS. Fresh D-MEM supplemented with $2 \%$ fetal calf serum (FCS) was added and the cells were incubated for $48 \mathrm{~h}$ at $37^{*} \mathrm{C}$ in $5 \% \mathrm{CO}_{2}$. It was considered that animals were infected if the cell monolayer presented cytopathic effects after a blind passage, as established in previous studies (Gnazzo et al., 2020; V. Quattrocchi et al., 2014; V Quattrocchi et al., 
2011; Zamorano et al., 2010). Percentages of protection were calculated as: $100 \mathrm{x}$ [protected/challenged mice]. A dose of $0.5 \mu \mathrm{g}$ VLPs induced $40 \%$ of protection and was thus selected for subsequent experiments, since it allows a good margin to observe the adjuvant effects.

\subsection{Adjuvants}

ISPA adjuvant is composed of alpha-tocopherol (TOCOP), phospatidylcholine (DPPC), stearylamine (STEA), cholesterol (CHOL) and QuilA saponin. The ISPA particles have a cage-like structure of 73.0 $\pm 1.5 \mathrm{~nm}$ in size as assessed by dynamic light scattering. First, liposomes were prepared with final proportions of TOCOP: $0.00074 \%$ (0.017 mM), DPPC: $0.320 \%$ (4.35 mM), STEA: 0.0216\% (0.8 mM) and CHOL: $0.143 \%(3.70 \mathrm{mM})$. Then, the suspension was extruded through a $50 \mathrm{~nm}$ pore membrane and a QuilA saponin solution in acetate buffer was added to liposomes $(6.5 \mathrm{mg} / 300 \mu \mathrm{l}$ per $\mathrm{ml}$ of liposomes) and extruded through a $50 \mathrm{~nm}$ membrane pore (Bertona et al., 2017; Prochetto et al., 2017).

The commercial oil adjuvant (CA) used was ISA206 (Seppic, Paris, France). The formulations were prepared following the manufacturer's indications in a proportion adjuvant: antigen 60:40.

\subsection{Vaccine formulations and vaccination experiments}

The vaccines to be applied in mice were formulated with: (i) $0.5 \mu \mathrm{g}$ VLPs in PBS (VLPs); (ii) $0.5 \mu \mathrm{g}$ VLPs in PBS mixed with $6 \mu \mathrm{l}$ ISPA (VLPs-ISPA) or (iii) $0.5 \mu \mathrm{g}$ VLPs in PBS mixed with CA (VLPs-CA), in a final volume of $0.1 \mathrm{ml} /$ dose. BALB/c mice were s.c. immunized at day 0 and 21 with: (i) VLPs (n=5); (ii) VLPs-ISPA ( $=5)$; (iii) VLPs-CA ( $\mathrm{n}=5)$; (iv) Commercial Vaccine $(\mathrm{C}+)(\mathrm{n}=5)$; (v) $6 \mu$ ISPA (n= 2); (vi) $(\mathrm{CA})(\mathrm{n}=2)$ or (vii) PBS $(\mathrm{n}=2)$. Mice were challenged at $36 \mathrm{dpv}$ as described in 2.4. The commercial vaccine consisted in a water-in-oil single emulsion containing O1/Campos/Brazil/58, A24/Cruzeiro/Brazil/55, C3/Indaial/Brazil/71 and A/Argentina/2001 iFMDV and was provided by Biogénesis Bagó S.A.

The vaccines used in cattle were formulated with (i) $25 \mu \mathrm{g}$ VLPs in PBS (VLPs); (ii) $25 \mu \mathrm{g}$ VLPs with 1 ml ISPA (VLPs-ISPA); (iii) $25 \mu \mathrm{g}$ VLPs in PBS mixed with CA (VLPs-CA); or (iv) $25 \mu \mathrm{g}$ iFMDV in PBS mixed with CA (iFMDV-CA), in a final volume of $2 \mathrm{ml} /$ dose. Cattle were s.c. vaccinated with: (i) VLPs $(\mathrm{n}=4)$; (ii) VLPs-ISPA ( $\mathrm{n}=4)$; (iii) VLPs-CA ( $\mathrm{n}=4)$ or (iv) iFMDV-CA $(\mathrm{n}=2)$.

\subsection{Measurement of total IgG and isotypes against FMDV by sandwich ELISA}

Total Abs against FMDV were assessed by ELISA as described previously (Batista et al., 2010; V Quattrocchi et al., 2011; Zamorano et al., 2010). Briefly, Greiner Microlonß plates were coated $\mathrm{ON}$ at $4^{\circ} \mathrm{C}$ with antiFMDV rabbit serum in carbonate-bicarbonate buffer, $\mathrm{pH}$ 9.6. After three washing steps, plates were blocked for $30 \mathrm{~min}$ at $37^{\circ} \mathrm{C}$ with polyvinylpyrrolidone blocking solution in the case of mouse sera $(0.5 \mathrm{M} \mathrm{NaCl} / 0.01$ M phosphate buffer/ 0.05\% Tween-20/ $1 \mathrm{mM}$ EDTA/ 1\% polyvinylpyrrolidone 30-40 K, pH 7.2) or with PBS / $10 \%$ fetal calf serum (FCS) in the case of bovine sera. An optimal dilution of inactivated FMDV in blocking solution was added, followed by incubation at $37^{*} \mathrm{C}$ for $30 \mathrm{~min}$. Then, serially diluted mouse sera (1:4) or bovine sera (1:5) in blocking solution were added. After $1 \mathrm{~h} 20 \mathrm{~min}$ incubation at room temperature, plates were washed and an optimal dilution of horse radish peroxidase (HRP)-conjugated anti-mouse IgG $(\mathrm{H}+\mathrm{L})(\mathrm{KPL}(\mathrm{r}))$, anti-mouse isotypes (Southern Biotech(r)), anti-bovine IgG $(\mathrm{KPL}(\mathrm{r}))$ or anti-bovine IgG1 or IgG2 $(\mathrm{KPL}(\mathrm{r}))$ were added. Plates were incubated for $1 \mathrm{~h}$ at room temperature and then washed. Orthophenylene-diamine (1,2-benzenediamine) dihydrochloride (SIGMA(r)) (OPD)/ $\mathrm{H}_{2} \mathrm{O}_{2}$ was used as peroxidase substrate. Reactions were stopped using $1.25 \mathrm{M} \mathrm{H}_{2} \mathrm{SO}_{4}$ and $\mathrm{A}_{492}$ was measured in a microplate reader. Positive and negative control sera were included in every plate. The cut-off was established as the mean of the values of negative sera $(n=10)$ plus two standard deviations.

\subsection{Measurement of total FMDV-specific Abs by liquid phase ELISA}

An lpELISA test was used according to Hamblin et al (1986), with modifications (Hamblin et al., 1986; OIE World Organisation for Animal Health, 2012) \sout. Briefly, Greiner Microlon(r) plates were coated overnight at $4{ }^{\circ} \mathrm{C}$ with rabbit anti-FMDV serum diluted to a previously established optimal concentration in carbonatebicarbonate buffer, pH 9.6. After washing with $0.05 \%$ Tween-20/phosphate buffered saline (PBST), plates 
were blocked with PBST/1\% ovalbumin (blocking buffer) for 30 min at 37 degC. Mice or bovine sera were serially diluted (1:10) in blocking buffer in separate tubes and a fixed amount of inactivated FMDV was added. After $1 \mathrm{~h}$ incubation at $37 \mathrm{deg} \mathrm{C}$ with shaking, the virus-antibody mixtures were transferred to the blocked plates, and incubated for $1 \mathrm{~h}$ at $37 \mathrm{degC}$. An optimal dilution of guinea pig anti-FMDV serum in PBS $/ 2 \%$ normal bovine serum $/ 2 \%$ normal rabbit serum was added for detection, followed by $1 \mathrm{~h}$ incubation at 37degC. Plates were washed and peroxidase-conjugated anti-guinea pig IgG (Jackson ImmunoResearch(r)) serum diluted in the same buffer was added, followed by $1 \mathrm{~h}$ incubation at $37 \mathrm{degC}$. OPD $/ \mathrm{H}_{2} \mathrm{O}_{2}$ was used as peroxidase substrate as above and $\mathrm{A}_{492}$ was measured in a microplate reader. Strong positive, weak positive and negative bovine reference sera were included in each test for validation. Antibody titers were expressed as the negative logarithm of the highest dilution of serum that causes an inhibition of color development higher than $50 \%$ in the average values of the control samples.

\subsection{Neutralizing Antibody Titers}

Serum samples were examined for anti-FMDV neutralizing Abs as described before (V. Quattrocchi et al., 2014). Briefly, serial dilutions of complement-inactivated sera were incubated for $1 \mathrm{~h}$ at $37 \mathrm{degC}$ with 100 TCID $_{50}$ of infective FMDV. Then virus-serum mixtures were seeded on BHK-21 monolayers. After 40 min at $37 \mathrm{degC}$, fresh DMEM $/ 2 \%$ FCS was added to the monolayers, which were incubated at $37 \mathrm{degC}$, under $5 \% \mathrm{CO}_{2}$. Cytopathic effects were observed after $48 \mathrm{~h}$.

\subsection{Lymphoproliferation assay}

Murine splenocytes were labeled with $3 \mu \mathrm{M}$ carboxyfluorescein diacetate succinimidyl ester (CFSE) in PBS for $30 \mathrm{~min}$ at $37^{\circ} \mathrm{C}$. Labeled cells were added to 96 -well plates $\left(5 \times 10^{5}\right.$ cell/well) in complete RPMI 1640 medium supplemented with $10 \%$ FCS and $50 \mathrm{mM}$ 2-mercaptoethanol, and were subjected to: (i) no stimulation (mock), (ii) $2.5 \mu \mathrm{g} / \mathrm{ml}$ iFMDV or (iii) $5 \mu \mathrm{g} / \mathrm{ml}$ Concanavalin A (Sigma Aldrich@, St. Louis, MO) as positive control. Cells were incubated at $37^{\circ} \mathrm{C}$ in $5 \% \mathrm{CO}_{2}$ atmosphere for 4 days and then fixed with $0.2 \%$ paraformaldehyde. Cell proliferation was analyzed by flow cytometry using FACSCaliburß (Becton Dickinson, San Jose, CA) and Flowing Software (Turku Centre for Biotechnology, Finland). Results were expressed as delta proliferation and were calculated as the difference between the percentage of proliferating cells stimulated with inactivated FMD virus and the percentage of proliferating cells without stimuli.

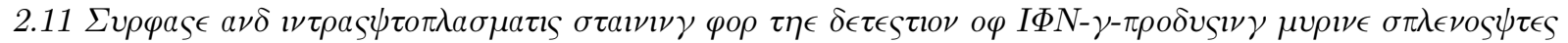

Murine splenocytes were incubated in complete RPMI 1640 medium supplemented with $10 \%$ FCS and 50 $\mathrm{mM} 2$-mercaptoethanol and were subjected to: (i) no stimulation ( mock), (ii) $2.5 \mu \mathrm{g} / \mathrm{ml}$ iFMDV or (iii) 5 $\mu \mathrm{g} / \mathrm{ml}$ Concanavalin A (Sigma Aldrich@, St. Louis, MO) as positive control. Cells were incubated for 18 $\mathrm{h}$ in the presence of brefeldin A (BD GolgiPlug), according to the manufacturer's recommendations. After washing, cells were fixed in $0.5 \%$ paraformaldehyde and permeated with saponin (0.1\% in PBS). Permeated cells were incubated for $20 \mathrm{~min}$ at RT with allophycocyanin (APC) anti-mouse INF- $\gamma$ (clone XMG1.2, BD Pharmingen ( $\mathrm{B}$ ) or isotype-matched control Abs. After $20 \mathrm{~min}$, cells were washed twice and stained for 30

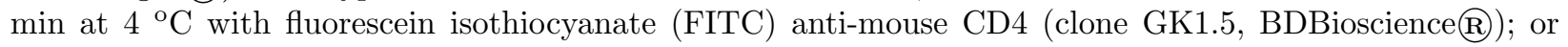

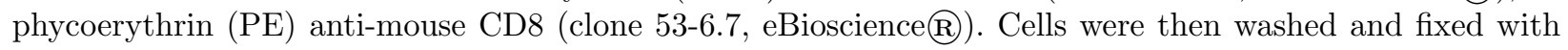
$0.2 \%$ paraformaldehyde. Flow cytometry was performed as in 2.10 (Supplementary figure 1).

\section{$2.12 I \Phi N-\gamma \delta \epsilon \tau \epsilon \varsigma \tau \imath O \nu$}

Peripheral blood mononuclear cells (PBMC) were obtained from cattle as described before (Romera et al., 2014). PBMC were cultured with $5 \mu \mathrm{g} / \mathrm{ml}$ iFMDV for 5 days. Supernatants were analyzed using ELISA as described previously (V. Quattrocchi et al., 2014). Briefly, plates were coated with a mAb against IFN- $\gamma$ (kindly donated by Dr. L. Babiuk). Samples and recombinant IFN- $\gamma$ standard (Serotec, UK) were added and IFN- $\gamma$ was detected using rabbit polyclonal anti-IFN- $\gamma$ Abs. After incubation, biotinylated goat antirabbit IgG antibody was added, followed by HRP-conjugated streptavidin (KPL, USA). Plates were washed, incubated with (OPD) $-\mathrm{H}_{2} \mathrm{O}_{2}$ and read at $492 \mathrm{~nm}$. IFN- $\gamma$ concentration was calculated from interpolation of data in a standard curve. 


\subsection{Statistical analysis}

GraphPad InStat@ program (GraphPad, California, USA) was used. Differences between groups were analyzed by applying the non-parametric Kruskal-Wallis test, followed by Mann-Whitney U-test for comparisons between two groups. $\mathrm{P}$ value $<0.05$ was considered as an indicator of significant differences.

\section{Results}

\subsection{Selection of the VLPs dose for vaccine formulation with adjuvants}

To analyze the modulatory effect of ISPA on the immune response to VLPs, a dose of VLPs capable of inducing $40 \%$ protection was first selected. To this end, mice were vaccinated with $8,4,2,1,0.5,0.3$ or 0.1 $\mu \mathrm{g}$ VLPs in PBS at 0 and $21 \mathrm{dpv}$ and challenged with infectious FMDV, serotype A/Argentina/2001 after $36 \mathrm{dpv}$. A dose-dependent decrease in antibody titers with decreasing amounts of VLPs (Figure 1A), as well as a concomitant protective effect were observed (Figure 1B). Forty percent of mice vaccinated with $0.5 \mu \mathrm{g}$ VLPs were protected upon viral challenge. Thus, this dose was chosen for vaccine formulations to detect the action of ISPA on the immune response against FMDV.

\subsection{A VLPs-ISPA vaccine confers total protection against FMDV in a murine model}

The protective efficacy of the inclusion of ISPA as adjuvant in a VLPs vaccine (VLPs-ISPA) was tested in mice. Groups of mice were vaccinated with VLPs, VLPs-ISPA, VLPs-CA, Commercial vaccine, CA alone, ISPA alone or PBS (negative controls) at 0 and $21 \mathrm{dpv}$. Then, mice were challenged with infective FMDV at $36 \mathrm{dpv}$ (Figure 2). Notably, while protection with VLPs alone was achieved in $40 \%$ of mice, inclusion of ISPA in the formulation increased protection levels to $100 \%$ as well as with the VLPs-CA and commercial vaccines. Animals inoculated with CA, ISPA or PBS were not protected, indicating that the viral challenge was conducted properly and indicates that protection depends on the inclusion of antigen in the vaccine.

\subsection{Murine specific anti-FMDV Abs and neutralizing Abs are increased when ISPA is used as adjuvant}

Antibody responses elicited by VLPs, VLPs-ISPA, VLPs-CA, Commercial vaccine, CA, ISPA and PBS were evaluated at 15, 21 and $36 \mathrm{dpv}$. Total specific anti-FMDV Ab titers measured by sandwich ELISA were significantly higher in the VLPs-ISPA and VLPs-CA groups as compared to the VLPs group ( $<0.01$ ) (Figure 3A). Importantly, when the virus neutralization test (VNT) was applied (Table 1), neutralizing antibody titers at $36 \mathrm{dpv}$ were significantly higher in groups vaccinated with VLPs-ISPA, VLPs-CA and Commercial vaccine, than in the VLPs group $(\mathrm{p}<0.05, \mathrm{p}<0.05$ and $\mathrm{p}<0.001$ respectively). VNT in the VLPs-CA and Commercial vaccine groups were similar. No neutralizing Abs were detected in the CA, ISPA and PBS groups.

Analysis of isotype profiles at $36 \mathrm{dpv}$ showed that the VLPs-ISPA group achieved higher IgG1 titers than all other groups $(\mathrm{p}<0.001)$. Moreover, IgG1 titers in the VLPs-CA and Commercial vaccine groups were similar (Figure 3B). IgG2a titers were also higher in: VLPs-ISPA, VLPs-CA and Commercial vaccine groups than in the VLPs group $(\mathrm{p}<0.001)$. Finally, IgG3 titers in the VLPs-ISPA group were significantly higher than IgG3 titers in the VLPs and VLPs-CA groups $(\mathrm{p}<0.001$ and $\mathrm{p}<0.01$ respectively) and similar to the titers elicited by the Commercial vaccine. Moreover, the IgG3 titer in VLPs-CA group was significantly higher than in the VLPs group.

3.4 Immunization with VLPs-ISPA and VLPs-CA induces a specific cellular immune response against FMDV in mice

At $36 \mathrm{dpv}$, when splenocytes were stimulated in vitro with inactivated virus, FMDV-specific T-cell stimulation levels were significantly higher in cells derived from mice immunized with VLPs-ISPA and VLPsCA $(\mathrm{p}<0.05)$ or with the Commercial vaccine $(\mathrm{p}<0.001)$ than in those derived from VLPs, ISPA or PBSinoculated mice (Figure 4). 


\subsection{VLPs plus ISPA or CA induce increased levels of anti-FMDV Abs in cattle}

After promising results obtained in the murine model, the immune efficacy of the VLPs-ISPA and VLPs-CA vaccines was studied in cattle, a natural host of the virus.

FMDV-serologically negative calves (per group) were inoculated only once with VLPs $(\mathrm{n}=4)$, VLPs-ISPA $(\mathrm{n}=4)$, VLPs-CA $(\mathrm{n}=4)$ or iFMDV-CA $(\mathrm{n}=2)$ at day 0 . The same amount of VLPs or iFMDV $(25 \mu \mathrm{g})$ was used in all formulations.

When Abs were measured by Lp ELISA, calves vaccinated with VLPs-ISPA and VLPs-CA displayed an increment in the elicited anti-FMDV humoral response as compared to animals vaccinated with VLPs alone $(\mathrm{p}<0.01)$ at 15, 30 and $45 \mathrm{dpv}$ (Figures 5A). Moreover, the FMDV humoral response achieved in VLPs-ISPA and VLPs-CA vaccinated animals was similar to that achieved in iFMDV-CA vaccinated animals.

Analysis of IgG1 isotype at $45 \mathrm{dpv}$ showed that, in cattle vaccinated with VLPs, VLPs-ISPA or VLPs-CA, no significant differences were detected between groups, although while in the group vaccinated with VLPs, the mean titer of IgG1 Abs was 2.5, the mean titers in the other groups were [?] 3. (Figure 5B). Moreover, the VLPs-ISPA and VLPs-CA vaccines achieved higher IgG2 levels than the VLPs vaccine $(\mathrm{p}<0.01)$.

FMDV-neutralizing Abs elicited in bovines by the different vaccines were next studied due to their connection with protection against viral challenge.

At $45 \mathrm{dpv}$, VNT results (Table 2$)$ showed a significant increase $(\mathrm{p}<0.001)$ in mean VNT titers in the VLPsISPA and VLPs-CA groups ( $2.1 \pm 0.1$ and $2.4 \pm 0.2$ respectively) compared with the VLPs group. Animals vaccinated with iFMDV-CA also presented high levels of neutralizing Abs (2.45 \pm 0.07$)$. Remarkably, these values have been reported to be associated with $90 \%$ Expected Percentage of Protection (EPP) (Maradei et al., 2008), which estimates the likelihood that cattle would be protected against a challenge of 10.000 bovine infective doses after vaccination (OIE - World Organisation for Animal Health, 2012).

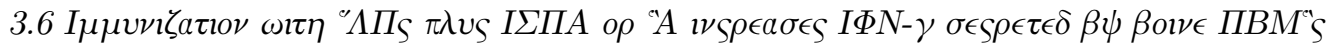

IFN- $\gamma$ levels were measured in the supernatant of PBMC cultures from vaccinated bovines. At $45 \mathrm{dpv}$, the group immunized with VLPs-ISPA reached significantly higher levels of IFN $\gamma$ than those inoculated with VLPs alone $(\mathrm{p}<0.05)$ (Figure 6).

\section{Discussion}

Current vaccines against FMD consist in inactivated FMDV plus an oil-adjuvant. The virus is produced in suspension-growing BHK-21 cells and then inactivated with binary ethyleneimine (BEI) (Doel, 2003; OIE - World Organisation for Animal Health Act N²2, 2018). This process needs high biosafety production facilities (BSL-4 OIE or higher), but requires strict protocols of production and constant investments in manufacturing plant up-grades and personnel qualifications. In addition, oil adjuvants as imports increase the costs of vaccines, especially in developing countries. Because of this, a new formulation using recombinant VLPs and a low-cost adjuvant that can be locally prepared are a good alternative to the marketed vaccine.

In this work, we examined the capacity of ISPA, a new cage-like particle adjuvant to elicit a protective and specific immune response against FMDV when used in VLPs-based vaccines. For that purpose, we used a mouse model developed in our laboratory, in which the humoral and protective immune responses against FMDV in mice correlate with those elicited in cattle (Batista et al., 2010; Bidart et al., 2020; C Langellotti et al., 2012; Cecilia Langellotti et al., 2015; V Quattrocchi et al., 2011, 2013; Valeria Quattrocchi et al., 2005; Romanutti et al., 2013; Zamorano et al., 2010).

In the murine model, the use of ISPA in VLPs-based vaccines allowed to achieve 100\% protection against viral challenge while the use of VLPs alone induced a protective response in only $40 \%$ of the animals. VLPs induced similar protection levels when using ISPA as adjuvant or CA. Animals vaccinated with adjuvant alone were not protected against viral challenge, showing that the protective response corresponded to an adaptive response against the virus and was not due to innate immune mechanisms elicited by the adjuvant. 
Ab titers against FMDV were significantly elevated in mice that received VLPs-ISPA as compared to the group vaccinated with VLPs alone and similar to the Ab titers induced by the VLPs-CA vaccine. These results correlate with the protection induced upon challenge It is important to mention that the levels of protection achieved were the same as those induced by the Commercial Vaccine (positive control) based on inactivated virus. It is noteworthy that neutralizing antibody titers showed a good correlation with protection levels, substantiating the notion that they are an in vitro reflection of the immune response that occurs in vivo (Mattion et al., 2009; McCullough et al., 1992; OIE - World Organisation for Animal Health, 2012). Also, Ab titers against FMDV and VNT values induced in mice by VLPs-ISPA and VLPs-CA were higher than the response induced by VLPs alone. Furthermore, these humoral responses elicited by VLPsISPA and VLPs-CA vaccines were enough to induce a $100 \%$ protection against viral challenge, in a similar way to the protection levels achieved with the commercial vaccine containing the inactivated virus. Noteworthy, the commercial vaccine contains FMDV serotype O1/Campos/Brazil/58, A24/Cruzeiro/Brazil/55, C3/Indaial/Brazil/71 and A/Argentina/2001, all of which bear epitopes that participate in the immune response against FMDV (Mattion et al., 2004)

When isotype profiles were characterized, increases in IgG1, IgG2a, IgGb and IgG3 isotype levels were observed in the VLPs-ISPA, VLP-CA and Commercial vaccine groups as compared to the group inoculated with VLPs alone. Interestingly, a prevalence of IgG1 and IgG2b isotypes was detected in animals vaccinated with VLPs-ISPA. These are promising results because Gnazzo et al (2020) reported that in the mouse model, IgG1 and IgG2b isotypes are important in the protection against FMDV O1 Campos \sout. VLPsISPA-vaccinated animals showed higher IgG3 isotype levels than the VLPs-CA group. It is well described that IgG1 and IgG3-FMDV immune complexes are recognized by Fc $\gamma$ RI receptors, present in macrophages, monocytes and dendritic cells, leading to a virus clearance (van der Poel et al., 2011). Thus, this mechanism could be involved in VLPs-ISPA protection. Also, IgG2a, IgG2b and IgG3 isotypes play a significant role in FMDV clearance trough complement-mediated phagocytosis (McCullough et al., 1988; Pérez Filgueira et al., 1995). Moreover, it has been reported that mice inoculated with inactivated FMDV plus some adjuvants generate a complement-fixing IgG profile that correlates with protection upon FMDV challenge (Batista et al., 2010; Pérez Filgueira et al., 1995). The different isotype profiles elicited by inoculation with these vaccines indicate a balanced Th1/Th2 response.

Regarding the cellular immune response obtained in mice using the experimental vaccines, both VLPs-ISPA and VLPs-CA induced an increased response compared to the VLPs group. These results suggest that ISPA and the Commercial Adjuvant improve the adaptive immune response against FMDV.

The VLPs-ISPA vaccine triggered proliferation and IFN $\gamma$ production in FMDV-specific CD8+ T lymphocytes, as occurred in mice vaccinated with inactivated FMDV (C Langellotti et al., 2012; Ostrowski et al., 2005). Similar results were obtained in the VLPs-CA group. Surprisingly, in the group immunized with Commercial Vaccine, although lymphoprolferation was observed when splenocytes were stimulated with inactivated virus, IFN $\gamma$ secretion only by CD4+ cells, but not by CD8+ cells, was registered (Supplementary Figure 1).

Previous studies described that ISCOMs improve the dendritic cell cross-presentation (den Brok et al., 2016; Maraskovsky et al., 2009; Wilson et al., 2012, 2014). The results described in the present work indicate that the VLPs- ISPA formulation generates a strong cellular response in agreement with previous reports that used cage like particles (Bertona et al., 2017; Prochetto et al., 2017).

The results of the humoral immune response profiles obtained in the murine model were further confirmed in calves, as was reported by Gnazzo et al. (2020) (Gnazzo et al., 2020).

Numerous studies performed in cattle show a correlation between Ab titers against FMDV elicited by vaccination and in vitro andin vivo protection upon experimental viral challenge. These correlations have allowed to estimate the Expected Percentage of Protection (EPP) to the homologous infection using titers of systemic $\alpha$-FMDV Ab measured by lpELISA or viral seroneutralization (Maradei et al., 2008; Mattion et al., 2009; OIE - World Organisation for Animal Health, 2012). 
In calves, one dose of the VLPs-ISPA formulation elicited total and neutralizing anti-FMDV Ab titers corresponding to an Expected Percentage of Protection (EPP) above 90\%, similar to those obtained with inactivated FMDV and CA (Maradei et al., 2008; Robiolo et al., 2010; Servicio Nacional de Sanidad y Calidad Agroalimentaria Res 609/2017. CABA, Argentina, 2017). Importantly, an acceptable inactivated vaccine should induce $75 \%$ protection in cattle (OIE - World Organisation for Animal Health, 2012).

Moreover, IgG2 titers were higher in VLPs plus adjuvant formulations which is related to pathogen opsonization. Bovine macrophages and neutrophils possess an immunoglobulin receptor to which IgG2 can bind (Tizard, 1998). On the other hand, we detected a significant increase in IFN- $\gamma$ secretion in cattle vaccinated with VLPs-ISPA as compared to cattle vaccinated with VLPs alone or VLPs-CA. IFN- $\gamma$ has been reported to display activity against FMDV (Summerfield et al., 2009), by controlling viral replication and spreading within the host through natural killer cell and macrophage activation (Zhang et al., 2002). Our data of increased IFN- $\gamma$ and increased presence of IgG2 in animals vaccinated with VLPs-ISPA, correlate with what was found by other researchers. Thus, a positive correlation between IFN- $\gamma$ response and vaccineinduced protection as well as reduction of long-term persistence of FMDV has been observed in cattle (Oh et al., 2012). In addition, IFN- $\gamma$ production is associated with a Th1 profile and an increased IgG2 production (Estes \& Brown, 2002). The numbers of cattle included in this pilot study were as those used in other preliminary studies on vaccine candidates (Bachmann \& Zinkernagel, 1997; Lee et al., 2005), although they were insufficient for statistical analysis (Soria et al., 2017). However, the results obtained serve as a proof of concept of the usefulness of VLPs as antigen and ISPA as adjuvant in FMDV vaccines. Although in calves, the iFMDV-CA group is too small to make any statistical comparisons, the neutralizing Ab titters induced by the vaccine containing the complete inactivated FMDV and commercial adjuvant were similar to those induced by VLPs with ISPA or CA.

The action of ISPA was similar in terms of levels, kinetics and profiles of humoral responses than the commercial oil adjuvant used in this study. ISPA has also been reported to have a better performance than ISCOMATRIX (Bertona et al., 2017). Importantly, particle size and adjuvant performance were conserved during a six-month period after preparation (Bertona et al., 2017). Future work will be devoted to examine whether ISPA exerts its action of enhancement of the immune response and protection levels by promoting the virus presentation to the immune effectors. Some authors have reported that ISCOMs induce local recruitment, activation and maturation of immune cells, such as dendritic cells, granulocytes, F4/80 int cells, T-, B- and NK-cells (Reed et al., 2009; Reimer et al., 2012; Sun et al., 2009), increasing in this way the chances of the antigen to come in contact with immune cells. In addition, Brok et al. (2016) proved that saponin-based adjuvants enhance antigen cross-presentation by dendritic cells and T-cell activation (den Brok et al., 2016). Immunization with a formulation based on Tripanosoma cruzi recombinant transialidase (mTS) and ISPA elicited high levels of protection upon challenge (Bertona et al., 2017). Moreover, this vaccine favorably modulates the regulatory arm of the immune system to reach immune protection against the parasite (Prochetto et al., 2017).

Noteworthy, VLPs-ISPA and VLPs-CA elicit high FMDV Ab titers. In cattle, the immune response elicited by FMDV (A22 Iraq strain) VLPs produced using the baculovirus technology and oil adjuvant was analyzed in a study by Porta et al. (2013) (Porta et al., 2013). Two vaccinations with $12 \mu \mathrm{g} / \mathrm{dose}$ elicited neutralizing Abs and $50 \%$ protection against challenge. When the capsids were mutated to increase their stability, the protection levels induced were of $75 \%$. In another study, Li et al (2012) showed $80 \%$ protection with one dose of A/WH/CHA/09 VLPs-ISA206 formulation (Li et al., 2012). Our results show a comparable or higher performance of the VLPs/ISPA and VLPs/CA formulations since with one $25 \mu \mathrm{g}$ dose, the levels of induced neutralizing Abs correlate with $90 \%$ of protection.

The recombinant VLPs used in this study were produced by transient transfection of suspension-growing mammalian cell cultures in serum free medium using a pTT5-based plasmid. This technology is a safe and cost-effective method of antigen production to develop a new non-infectious vaccine for controlling FMD in vaccination-free countries, as well as in FMD-endemic countries and in the event of an outbreak.

In conclusion, ISPA is a new cage-like particle adjuvant that can be used in combination with recombinant 
VLPs to develop a novel vaccine against FMD. Results showed ISPA is useful in increasing and modulating the humoral and cellular responses in vaccinated mice and cattle, yielding enhanced protection against challenge. Taken together, these results are promising for the development of a novel FMD vaccine with a recombinant, non-infectious antigen and a new, cost-effective and innovative adjuvant.

\section{Acknowledgments}

The authors acknowledge the skilled assistance of Mr. Diego Compaired with cell cultures and the technical help of Ms. Pamela Angeletti, the valuable work of BSc Juan Schammas and Eng. Javier Rosende in the BSL-4OIE facilities at CICVyA-INTA, the technical assistance at INTA bioterium of Eng. Gabriel Pinto and Ms. Sandra Rivarola, the help with flow cytometer measurements of Ms. Paula Blanco from CIO-FUCA and BSc. Julieta Alcain from IMEX-CONICET, and the provision of A/Argentina/2001 binary ethylene-imine (BEI)-inactivated FMDV by Biogenesis Bago S.A.

\section{Declaration of Interest Statement}

The authors declare that the research was conducted in the absence of any commercial or financial relationships that could be construed as a potential conflict of interest.

Cardillo S, employee of Biogénesis Bagó, declares that its judgment and objectivity was not biased by their contractual condition.

\section{Data Availability Statement}

\section{The datasets generated for this study are available on request to the corresponding author}

\section{Ethics Statement}

The animal study was reviewed and approved by Comité Institucional para el Cuidado y Uso de Animales de Experimentación (CICUAE) - Centro de Investigación en Ciencias Veterinarias y Agronómicas del INTA.

\section{Author Contributions}

JEB: Conceptualization; Methodology; Formal analysis; Investigation; Writing - Original Draft; Visualization AM: Conceptualization; Methodology; Formal analysis; Resources; Writing - Original Draft

CK: Validation; Investigation

GL: Validation; Investigation, Resources;

MG: Validation; Investigation

IS: Validation; Formal analysis

RG: Validation; Investigation

CS: Resources, Writing Review \& Editing

CL: Methodology; Formal analysis; Investigation; Writing - Original Draft

VQ: Methodology; Formal analysis; Investigation; Writing - Original Draft 
YD: Conceptualization; Methodology, Resources;

WA: Conceptualization; Methodology; Writing - Review \& Editing

IM: Conceptualization; Methodology; Writing - Review \& Editing

PZ: Conceptualization; Methodology; Writing - Original Draft; Writing Review \& Editing, Visualization; Supervision; Project Administration; Funding adquisition

Acharya, R., Fry, E., Stuart, D., Fox, G., Rowlands, D., \& Brown, F. (1989). The three-dimensional structure of foot-and-mouth disease virus at $2.9 \AA$ resolution. Nature . https://doi.org/10.1038/337709a0

Bachmann, M. F., \& Zinkernagel, R. M. (1997). NEUTRALIZING ANTIVIRAL B CELL RESPONSES. Annual Review of Immunology . https://doi.org/10.1146/annurev.immunol.15.1.235

Baldi, L., Hacker, D. L., Adam, M., \& Wurm, F. M. (2007). Recombinant protein production by large-scale transient gene expression in mammalian cells: State of the art and future perspectives. In Biotechnology Letters . https://doi.org/10.1007/s10529-006-9297-y

Batista, A., Quattrocchi, V., Olivera, V., Langellotti, C., Pappalardo, J. S., Di Giacomo, S., Mongini, C., Portuondo, D., \& Zamorano, P. (2010). Adjuvant effect of Cliptox ${ }^{\mathrm{TM}}$ on the protective immune response induced by an inactivated vaccine against foot and mouth disease virus in mice. Vaccine , 28 (38), 6361-6366. https://doi.org/10.1016/j.vaccine.2010.06.098

Belsham, G. J. (2005). Translation and replication of FMDV RNA. InCurrent Topics in Microbiology and Immunology . https://doi.org/10.1007/3-540-27109-0_3

Bertona, D., Pujato, N., Bontempi, I., Gonzalez, V., Cabrera, G., Gugliotta, L., Hozbor, D., Nicastro, A., Calvinho, L., \& Marcipar, I. S. (2017). Development and assessment of a new cage-like particle adjuvant. Journal of Pharmacy and Pharmacology , 69 (10), 1293-1303. https://doi.org/10.1111/jphp.12768

Bidart, J. E., Kornuta, C., Gammella, M., Gnazzo, V., Soria, I., Langellotti, C. A., Mongini, C., Galarza, R., Calvinho, L., Lupi, G., Quattrocchi, V., Marcipar, I. S., \& Zamorano, P. I. (2020). A new cage-like particle adjuvant enhances protection of Foot and Mouth Disease vaccine. Frontiers in Veterinary Science (in Press) . https://doi.org/10.3389/fvets.2020.00396

Caridi, F., Vázquez-Calvo, A., Sobrino, F., \& Martín-Acebes, M. A. (2015). The pH Stability of Foot-andMouth Disease Virus Particles Is Modulated by Residues Located at the Pentameric Interface and in the N Terminus of VP1. Journal of Virology . https://doi.org/10.1128/jvi.03358-14

den Brok, M. H., Büll, C., Wassink, M., de Graaf, A. M., Wagenaars, J. A., Minderman, M., Thakur, M., Amigorena, S., Rijke, E. O., Schrier, C. C., \& Adema, G. J. (2016). Saponin-based adjuvants induce crosspresentation in dendritic cells by intracellular lipid body formation. Nature Communications , 7 (1), 13324. https://doi.org/10.1038/ncomms13324

Doel, T. R. (2003). FMD vaccines. Virus Research , 91 (1), 81-99. https://doi.org/10.1016/S01681702(02)00261-7

Ellard, F. M., Drew, J., Blakemore, W. E., Stuart, D. I., \& King, A. M. Q. (1999). Evidence for the role of His-142 of protein 1C in the acid-induced disassembly of foot-and-mouth disease virus capsids. Journal of General Virology . https://doi.org/10.1099/0022-1317-80-8-1911

Estes, D. M., \& Brown, W. C. (2002). Type 1 and type 2 responses in regulation of Ig isotype expression in cattle. Veterinary Immunology and Immunopathology , 90 (1-2), 1-10. https://doi.org/10.1016/S01652427(02)00201-5

Gnazzo, V., Quattrocchi, V., Soria, I., Pereyra, E., Langellotti, C., Pedemonte, A., Lopez, V., Marangunich, L., \& Zamorano, P. (2020). Mouse model as an efficacy test for foot-and-mouth disease vaccines. Transboundary and Emerging Diseases, tbed.13591. https://doi.org/10.1111/tbed.13591 
Grubman, M. J. (2005). Development of novel strategies to control foot-and-mouth disease: Marker vaccines and antivirals.Biologicals . https://doi.org/10.1016/j.biologicals.2005.08.009

Grubman, M. J., \& Baxt, B. (2004). Foot-and-Mouth Disease .17 (2), 465-493. https://doi.org/10.1128/CMR.17.2.465

Gullberg, M., Lohse, L., Botner, A., McInerney, G. M., Burman, A., Jackson, T., Polacek, C., \& Belsham, G. J. (2016). A Prime-Boost Vaccination Strategy in Cattle to Prevent Foot-and-Mouth Disease Using a "Single-Cycle" Alphavirus Vector and Empty Capsid Particles.PLOS ONE , 11 (6), e0157435. https://doi.org/10.1371/journal.pone.0157435

Hamblin, C., Barnett, I. T. R., \& Hedger, R. S. (1986). A new enzyme-linked immunosorbent assay (ELISA) for the detection of antibodies against foot-and-mouth disease virus I. Development and method of ELISA. Journal of Immunological Methods , 93 (1), 115-121. https://doi.org/10.1016/0022-1759(86)90441-2

Jackson, T., Sheppard, D., Denyer, M., Blakemore, W., \& King, A. M. Q. (2000). The Epithelial Integrin $\alpha \mathrm{v} \beta 6$ Is a Receptor for Foot-and-Mouth Disease Virus. Journal of Virology . https://doi.org/10.1128/jvi.74.11.4949-4956.2000

Kotecha, A., Seago, J., Scott, K., Burman, A., Loureiro, S., Ren, J., Porta, C., Ginn, H. M., Jackson, T., Perez-Martin, E., Siebert, C. A., Paul, G., Huiskonen, J. T., Jones, I. M., Esnouf, R. M., Fry, E. E., Maree, F. F., Charleston, B., \& Stuart, D. I. (2015). Structure-based energetics of protein interfaces guides foot-and-mouth disease virus vaccine design. Nature Structural 83 Molecular Biology ,22 (10), 788-794. https://doi.org/10.1038/nsmb.3096

Langellotti, C, Quattrocchi, V., Alvarez, C., Ostrowski, M., Gnazzo, V., Zamorano, P., \& Vermeulen, M. (2012). Foot-and-mouth disease virus causes a decrease in spleen dendritic cells and the early release of IFN- $\alpha$ in the plasma of mice. Differences between infectious and inactivated virus. Antiviral Research , 94 (1), 62-71. https://doi.org/https://doi.org/10.1016/j.antiviral.2012.02.009

Langellotti, Cecilia, Cesar, G., Soria, I., Quattrocchi, V., Jancic, C., Zamorano, P., \& Vermeulen, M. (2015). Foot-and-mouth disease virus infection of dendritic cells triggers phosphorylation of ERK1/2 inducing class I presentation and apoptosis. Vaccine . https://doi.org/10.1016/j.vaccine.2015.07.038

Lee, B. O., Rangel-Moreno, J., Moyron-Quiroz, J. E., Hartson, L., Makris, M., Sprague, F., Lund, F. E., \& Randall, T. D. (2005). CD4 T Cell-Independent Antibody Response Promotes Resolution of Primary Influenza Infection and Helps to Prevent Reinfection. The Journal of Immunology . https://doi.org/10.4049/jimmunol.175.9.5827

Li, Z., Yi, Y., Yin, X., Zhang, Y., Liu, M., Liu, H., Li, X., Li, Y., Zhang, Z., \& Liu, J. (2012). Development of a Foot-and-Mouth Disease Virus Serotype A Empty Capsid Subunit Vaccine Using Silkworm (Bombyx mori) Pupae. PLoS ONE , 7 (8), e43849. https://doi.org/10.1371/journal.pone.0043849

Maradei, E., La Torre, J., Robiolo, B., Esteves, J., Seki, C., Pedemonte, A., Iglesias, M., D’Aloia, R., \& Mattion, N. (2008). Updating of the correlation between lpELISA titers and protection from virus challenge for the assessment of the potency of polyvalent aphtovirus vaccines in Argentina. Vaccine , 26 (51), 65776586. https://doi.org/https://doi.org/10.1016/j.vaccine.2008.09.033

Maraskovsky, E., Schnurr, M., Wilson, N. S., Robson, N. C., Boyle, J., \& Drane, D. (2009). Development of prophylactic and therapeutic vaccines using the ISCOMATRIX adjuvant. Immunology and Cell Biology , 87 (5), 371-376. https://doi.org/10.1038/icb.2009.21

Mateo, R., Luna, E., Rincón, V., \& Mateu, M. G. (2008). Engineering Viable Foot-and-Mouth Disease Viruses with Increased Thermostability as a Step in the Development of Improved Vaccines. Journal of Virology . https://doi.org/10.1128/jvi.01553-08

Mattion, N., Goris, N., Willems, T., Robiolo, B., Maradei, E., Beascoechea, C. P., Perez, A., Smitsaart, E., 
Fondevila, N., Palma, E., De Clercq, K., \& La Torre, J. (2009). Some guidelines for determining foot-andmouth disease vaccine strain matching by serology. Vaccine . https://doi.org/10.1016/j.vaccine.2008.11.026

Mattion, N., Konig, G., Seki, C., Smitsaart, E., Maradei, E., Robiolo, B., Duffy, S., Leon, E., Piccone, M., Sadir, A., Bottini, R., Cosentino, B., Falczuk, A., Maresca, R., Periolo, O., Bellinzoni, R., Espinoza, A., Torre, J. La, \& Palma, E. L. (2004). Reintroduction of foot-and-mouth disease in Argentina: characterisation of the isolates and development of tools for the control and eradication of the disease. Vaccine ,22 (31-32), 4149-4162. https://doi.org/10.1016/j.vaccine.2004.06.040

McCullough, K. C., Bruckner, L., Schaffner, R., Fraefel, W., Muller, H. K., \& Kihm, U. (1992). Relationship between the anti-FMD virus antibody reaction as measured by different assays, and protection in vivo against challenge infection. Veterinary Microbiology , 30 (2-3), 99-112.

McCullough, K. C., Parkinson, D., \& Crowther, J. R. (1988). Opsonization-enhanced phagocytosis of footand-mouth disease virus.Immunology , 65 (2), 187-191.

Medina, G. N., Segundo, F. D.-S., Stenfeldt, C., Arzt, J., \& de los Santos, T. (2018). The Different Tactics of Foot-and-Mouth Disease Virus to Evade Innate Immunity. Frontiers in Microbiology ,9 (November), 1-22. https://doi.org/10.3389/fmicb.2018.02644

Mignaqui, A. C., Ruiz, V., Perret, S., St-Laurent, G., Singh Chahal, P., Transfiguracion, J., Sammarruco, A., Gnazzo, V., Durocher, Y., \& Wigdorovitz, A. (2013). Transient Gene Expression in Serum-Free SuspensionGrowing Mammalian Cells for the Production of Foot-and-Mouth Disease Virus Empty Capsids. PLOS ONE , 8 (8), e72800. https://doi.org/10.1371/journal.pone.0072800

Mohan, T., Verma, P., \& Rao, D. N. (2013). Novel adjuvants \& delivery vehicles for vaccines development: a road ahead. The Indian Journal of Medical Research , 138 (5), 779-795. http://www.ncbi.nlm.nih.gov/pubmed/24434331

Monaghan, P., Gold, S., Simpson, J., Zhang, Z., Weinreb, P. H., Violette, S. M., Alexandersen, S., \& Jackson, T. (2005). The $\alpha \mathrm{v} \beta 6$ integrin receptor for Foot-and-mouth disease virus is expressed constitutively on the epithelial cells targeted in cattle. Journal of General Virology . https://doi.org/10.1099/vir.0.81172-0

Morein, B., Sundquist, B., Höglund, S., Dalsgaard, K., \& Osterhaus, A. (1984). Iscom, a novel structure for antigenic presentation of membrane proteins from enveloped viruses. Nature . https://doi.org/10.1038/308457a0

Oh, Y., Fleming, L., Statham, B., Hamblin, P., Barnett, P., Paton, D. J., Park, J. H., Joo, Y. S., \& Parida, S. (2012). Interferon- $\gamma$ Induced by In Vitro Re-Stimulation of CD4+ T-Cells Correlates with In Vivo FMD Vaccine Induced Protection of Cattle against Disease and Persistent Infection. PLoS ONE . https://doi.org/10.1371/journal.pone.0044365

OIE - World Organisation for Animal Health Act $\mathrm{N}^{\circ} 22, \quad$ Pub. L. No. 22 (2018). http://www.oie.int/fileadmin/Home/esp/Animal_Health_in_the_World/docs/pdf/Resolutions/2018/E22_RESO_2018_FMD.pdf

OIE - World Organisation for Animal Health. (2012). Foot and Mouth Disease (infection with FMDV). In OIE 2012 (Ed.), OIE Terrestrial Manual (7 ${ }^{\circ}$ Edition, pp. 1-32). OIE 2012. https://books.google.com.ar/books?id=15b5AAAACAAJ

Ostrowski, M., Vermeulen, M., Zabal, O., Geffner, J. R., Sadir, A. M., \& Lopez, O. J. (2005). Impairment of Thymus-Dependent Responses by Murine Dendritic Cells Infected with Foot-and-Mouth Disease Virus. The Journal of Immunology . https://doi.org/10.4049/jimmunol.175.6.3971

Parida, S. (2009). Vaccination against foot-and-mouth disease virus: Strategies and effectiveness. In Expert Review of Vaccines . https://doi.org/10.1586/14760584.8.3.347 
Pérez Filgueira, D. M., Berinstein, A., Smitsaart, E., Borca, M. V., \& Sadir, A. M. (1995). Isotype profiles induced in Balb/c mice during foot and mouth disease (FMD) virus infection or immunization with different FMD vaccine formulations. Vaccine , 13 (10), 953-960. https://doi.org/10.1016/0264-410X(95)00078-F

Pham, P. L., Kamen, A., \& Durocher, Y. (2006). Large-scale transfection of mammalian cells for the fast production of recombinant protein.Molecular Biotechnology . https://doi.org/10.1385/MB:34:2:225

Porta, C., Kotecha, A., Burman, A., Jackson, T., Ren, J., Loureiro, S., Jones, I. M., Fry, E. E., Stuart, D. I., \& Charleston, B. (2013). Rational Engineering of Recombinant Picornavirus Capsids to Produce Safe, Protective Vaccine Antigen. PLoS Pathogens , 9 (3), e1003255. https://doi.org/10.1371/journal.ppat.1003255

Prochetto, E., Roldán, C., Bontempi, I. A., Bertona, D., Peverengo, L., Vicco, M. H., Rodeles, L. M., Pérez, A. R., Marcipar, I. S., \& Cabrera, G. (2017). Trans-sialidase-based vaccine candidate protects against Trypanosoma cruzi infection, not only inducing an effector immune response but also affecting cells with regulatory/suppressor phenotype. Oncotarget , 8 (35), 58003-58020. https://doi.org/10.18632/oncotarget.18217

Quattrocchi, V., Pappalardo, J. S., Langellotti, C., Smitsaart, E., Fondevila, N., \& Zamorano, P. (2014). Early protection against foot-and-mouth disease virus in cattle using an inactivated vaccine formulated with Montanide ESSAI IMS D 12802 VG PR adjuvant.Vaccine , 32 (19), 2167-2172. https://doi.org/10.1016/j.vaccine.2014.02.061

Quattrocchi, V, Langellotti, C., Pappalardo, J. S., Olivera, V., Di Giacomo, S., van Rooijen, N., Mongini, C., Waldner, C., \& Zamorano, P. I. (2011). Role of macrophages in early protective immune responses induced by two vaccines against foot and mouth disease. Antiviral Research , 92 (2), 262-270. https://doi.org/10.1016/j.antiviral.2011.08.007

Quattrocchi, V, Molinari, P., Langellotti, C., Gnazzo, V., Taboga, O., \& Zamorano, P. (2013). Coinoculation of baculovirus and FMDV vaccine in mice, elicits very early protection against foot and mouth disease virus without interfering with long lasting immunity. Vaccine ,31 (24), 2713-2718. https://doi.org/10.1016/j.vaccine.2013.03.067

Quattrocchi, Valeria, Bianco, V., Fondevila, N., Pappalardo, S., Sadir, A., \& Zamorano, P. (2005). Use of new adjuvants in an emergency vaccine against foot-and-mouth disease virus: Evaluation of conferred immunity.Developments in Biologicals , 119 , 481-497.

Reed, S. G., Bertholet, S., Coler, R. N., \& Friede, M. (2009). New horizons in adjuvants for vaccine development. Trends in Immunology , 30 (1), 23-32. https://doi.org/10.1016/j.it.2008.09.006

Reimer, J. M., Karlsson, K. H., Lövgren-Bengtsson, K., Magnusson, S. E., Fuentes, A., \& Stertman, L. (2012). Matrix-m ${ }^{\mathrm{TM}}$ adjuvant induces local recruitment, activation and maturation of central immune cells in absence of antigen. PLOS ONE . https://doi.org/10.1371/journal.pone.0041451

Rincón, V., Rodríguez-Huete, A., López-Argüello, S., Ibarra-Molero, B., Sanchez-Ruiz, J. M., Harmsen, M. M., \& Mateu, M. G. (2014). Identification of the structural basis of thermal lability of a virus provides a rationale for improved vaccines. Structure . https://doi.org/10.1016/j.str.2014.08.019

Robiolo, B., La Torre, J., Maradei, E., Beascoechea, C. P., Perez, A., Seki, C., Smitsaart, E., Fondevila, N., Palma, E., Goris, N., De Clercq, K., \& Mattion, N. (2010). Confidence in indirect assessment of footand-mouth disease vaccine potency and vaccine matching carried out by liquid phase ELISA and virus neutralization tests. Vaccine ,28 (38), 6235-6241. https://doi.org/10.1016/j.vaccine.2010.07.012

Rodriguez, L. L., \& Grubman, M. J. (2009). Foot and mouth disease virus vaccines. In Vaccine . https://doi.org/10.1016/j.vaccine.2009.08.039

Romanutti, C., D'Antuono, A., Palacios, C., Quattrocchi, V., Zamorano, P., La Torre, J., \& Mattion, N. (2013). Evaluation of the immune response elicited by vaccination with viral vectors encoding FMDV capsid proteins and boosted with inactivated virus. Veterinary Microbiology , 165 (3-4), 333-340. https://doi.org/10.1016/j.vetmic.2013.04.017 
Romera, S., Puntel, M., Quattrocchi, V., Zajac, P. Del, Zamorano, P., Blanco Viera, J., Carrillo, C., Chowdhury, S., Borca, M. V, \& Sadir, A. M. (2014). Protection induced by a glycoprotein E-deleted bovine herpesvirus type 1 marker strain used either as an inactivated or live attenuated vaccine in cattle. BMC Veterinary Research ,10 (1), 8. https://doi.org/10.1186/1746-6148-10-8

Servicio Nacional de Sanidad y Calidad Agroalimentaria Res 609/2017. CABA, Argentina, Resolución (2017).

Singh, M. (2006). Vaccine Adjuvants and Delivery Systems. In Vaccine Adjuvants and Delivery Systems . https://doi.org/10.1002/9780470134931

Soria, I., Quattrocchi, V., Langellotti, C., Gammella, M., Digiacomo, S., Garcia de la Torre, B., Andreu, D., Montoya, M., Sobrino, F., Blanco, E., \& Zamorano, P. (2017). Dendrimeric peptides can confer protection against foot-and-mouth disease virus in cattle. PloS One, 12 (9), e0185184. https://doi.org/10.1371/journal.pone.0185184

Summerfield, A., Guzylack-Piriou, L., Harwood, L., \& McCullough, K. C. (2009). Innate immune responses against foot-and-mouth disease virus: Current understanding and future directions. Veterinary Immunology and Immunopathology . https://doi.org/10.1016/j.vetimm.2008.10.296

Sun, H.-X., Xie, Y., \& Ye, Y.-P. (2009). ISCOMs and ISCOMATRIX. Vaccine, 27 (33), 4388-4401. https://doi.org/10.1016/j.vaccine.2009.05.032

Thompson, D., Muriel, P., Russell, D., Osborne, P., Bromley, A., Rowland, M., Creigh-Tyte, S., \& Brown, C. (2002). Economic costs of the foot and mouth disease outbreak in the United Kingdom in 2001. InOIE Revue Scientifique et Technique . https://doi.org/10.20506/rst.21.3.1353

Tizard, I. (1998). Inmunología Veterinaria, 5e(McGraw-HillInteramericana (ed.); 5e ed.). McGraw-Hill Interamericana Mexico.

van der Poel, C. E., Spaapen, R. M., van de Winkel, J. G. J., \& Leusen, J. H. W. (2011). Functional Characteristics of the High Affinity IgG Receptor, FcץRI. The Journal of Immunology . https://doi.org/10.4049/jimmunol.1003526

Wilson, N. S., Duewell, P., Yang, B., Li, Y., Marsters, S., Koernig, S., Latz, E., Maraskovsky, E., Morelli, A. B., Schnurr, M., \& Ashkenazi, A. (2014). Inflammasome-Dependent and -Independent IL-18 Production Mediates Immunity to the ISCOMATRIX Adjuvant. The Journal of Immunology , 192 (7), 3259-3268. https://doi.org/10.4049/jimmunol.1302011

Wilson, N. S., Yang, B., Morelli, A. B., Koernig, S., Yang, A., Loeser, S., Airey, D., Provan, L., Hass, P., Braley, H., Couto, S., Drane, D., Boyle, J., Belz, G. T., Ashkenazi, A., \& Maraskovsky, E. (2012). ISCOMATRIX vaccines mediate CD8 + T-cell cross-priming by a MyD88-dependent signaling pathway. Immunology $\& 3$ Cell Biology ,90 (5), 540-552. https://doi.org/10.1038/icb.2011.71

Xiao, Y., Chen, H.-Y., Wang, Y., Yin, B., Lv, C., Mo, X., Yan, H., Xuan, Y., Huang, Y., Pang, W., Li, X., Yuan, Y. A., \& Tian, K. (2016). Large-scale production of foot-and-mouth disease virus (serotype Asia1) VLP vaccine in Escherichia coli and protection potency evaluation in cattle. BMC Biotechnology , 16 (1), 56. https://doi.org/10.1186/s12896-016-0285-6

Zamorano, P., Decheneux, C., Quattrocchi, V., Olivera, V., Langellotti, C., DiGiacomo, S., Kahn, N., Trotta, M., Guinzburg, M., Sadir, A., \& Smitsaart, E. (2010). Vaccination against Foot-and-Mouth Disease, association between humoral immune response in cattle and mice. In OIE-IABS (Ed.), Practical Alternatives to Reduce Animal Testing in Quality Control of Veterinary Biologicals in the Americas (pp. 100-111). OIEIABS.

Zhang, Z. D., Hutching, G., Kitching, P., \& Alexandersen, S. (2002). The effects of gamma interferon on replication of foot-and-mouth disease virus in persistently infected bovine cells. Archives of Virology . https://doi.org/10.1007/s00705-002-0867-6 
Figure 1 . Selection of VLPs dose for vaccination of BALB/c mice. Groups of mice $(n=5)$ were vaccinated with $8,4,2,1,0.5,0.3,0.15$ or $0 \mu \mathrm{g}$ VLPs in PBS at 0 and 21 days and challenged with infective virus at 36 dpv. (A) Abs against FMDV elicited by vaccination with different amounts of VLPs measured by sandwich ELISA at 36 dpv. (B) Percentages of protected animals upon viral challenge. Animals were considered protected if viremia was absent at $24 \mathrm{~h}$ post challenge. Protection percentages were calculated as: $100 \mathrm{x}$ [number of vaccinated animals without viremia / number of vaccinated animals].

Figure 2 . Protection upon viral challenge elicited by experimental vaccines. Groups of mice $(\mathrm{n}=5)$ were vaccinated with VLPs $(0.5 \mu \mathrm{g})$, VLPs $(0.5 \mu \mathrm{g})$-ISPA, VLPs $(0.5 \mu \mathrm{g})-\mathrm{CA}$ or a Control $(+)$ vaccine, and groups of mice $(n=2)$ were vaccinated with ISPA, CA or PBS alone at $0 \mathrm{dpv}$ and $21 \mathrm{dpv}$, and challenged with infective FMDV at $36 \mathrm{dpv}$. Protection was calculated as in Figure 1.

Figure 3 . Abs against FMDV elicited by experimental vaccines in mice. FMDV specific antibody titers were measured by (A) sandwich ELISA at 15, 21 and 36 dpv. Each point represents the mean $(\mathrm{n}=5) \mathrm{Ab}$ titer $\pm \mathrm{SD}$ in each group. ${ }^{*}$ Significant differences against VLPs group. ${ }^{* *}(\mathrm{p}<0.01) ; * * *(\mathrm{p}<0.001) .(\mathrm{B})$ Isotype profile of vaccinated animals at $36 \mathrm{dpv}$. Data are expressed as the mean $\mathrm{Ab}$ titer $\pm \mathrm{SD}$. ${ }^{* * *} \mathrm{p}<$ $0.001, * *(\mathrm{p}<0.01)$.

Figure 4 . Lymphocyte proliferative response after stimulation with iFMDV measured by CFSE loss, at $36 \mathrm{dpv}$. Results are expressed as the difference $(\Delta \%)$ between the percentage of proliferating splenocytes stimulated with inactivated virus and the percentage of proliferating splenocytes without stimuli. Animals were vaccinated with VLPs, VLPs-ISPA, VLPs-CA, control (+) vaccine, ISPA, commercial adjuvant alone or PBS. ${ }^{* * *} \mathrm{p}<0.001 ;{ }^{*} \mathrm{p}<0.05$.

Figure 5. Humoral response elicited in cattle by experimental vaccines. FMDV-specific antibody titers were measured by Lp ELISA. (A) Kinetics of total anti-FMDV serum Abs. Each bar represents the mean $\mathrm{Ab}$ titer $\pm \mathrm{SD}(\mathrm{n}=4)$ at 15, 30 and $45 \mathrm{dpv}$. (B) FMDV-specific serum IgG1 and IgG2 response at $45 \mathrm{dpv}$. Each point represents the serum IgG1 or IgG2 anti-FMDV Ab titers ( $\log 10)$ of each animal. Isotype profiles at $45 \mathrm{dpv}$, expressed as mean Ab titers $\pm \mathrm{SD} .{ }^{* *} \mathrm{p}<0.01,{ }^{*} \mathrm{p}<0.05$.

Figure 6 . IFN- $\gamma$ production by PBMC from calves inoculated with experimental vaccines at $45 \mathrm{dpv}$. Cells were stimulated in vitro with iFMDV. Supernatants were tested by ELISA. Each bar represents the IFN $\gamma$ levels $(\mathrm{pg} / \mathrm{ml})$ secreted by PBMCs from each bovine when they were stimulated in vitro with iFMDV, ${ }^{*} \mathrm{p}<$ 0.05 .

Supplementary Figure 1. Flow cytometry analysis of CD4+/IFN $\gamma+$ and CD8+/IFN $\gamma+$ cell percentages. At $36 \mathrm{dpv}$, splenocytes from vaccinated BALB/c were (i) not stimulated stimulated (mock) or stimulated with (ii) $2.5 \mu \mathrm{g} / \mathrm{ml} \mathrm{iFMDV} \mathrm{or} \mathrm{(iii)} 5 \mu \mathrm{g} / \mathrm{ml}$ Concanavalin A as positive control. Cells were incubated for $18 \mathrm{~h}$ in the presence of brefeldin A. Permeated cells were incubated with anti-mouse INF- $\gamma$. Then, cells were stained with anti-mouse CD4 or anti-mouse CD8. Splenocytes were obtained from mice vaccinated with VLPs, VLPs-ISPA, VLPs-CA, Commercial vaccine, ISPA, CA alone or PBS. (A) Percentages of CD4+/IFN $\gamma+\mathrm{T}$ cells and (B) percentages of $\mathrm{CD} 8+/ \mathrm{IFN} \gamma+\mathrm{T}$ cells from mice spleens. ${ }^{* *} \mathrm{p}<0.01 ;{ }^{*} \mathrm{p}<0.05$.

\section{Hosted file}

2020-07-13_Table1.docx available at https://authorea.com/users/343216/articles/469872-ispacage-like-particle-adjuvant-enhances-protection-induced-by-a-arg-2001-foot-and-mouthdisease-virus-like-particles

\section{Hosted file}

2020-07-13_Table2.docx available at https://authorea.com/users/343216/articles/469872-ispacage-like-particle-adjuvant-enhances-protection-induced-by-a-arg-2001-foot-and-mouthdisease-virus-like-particles 

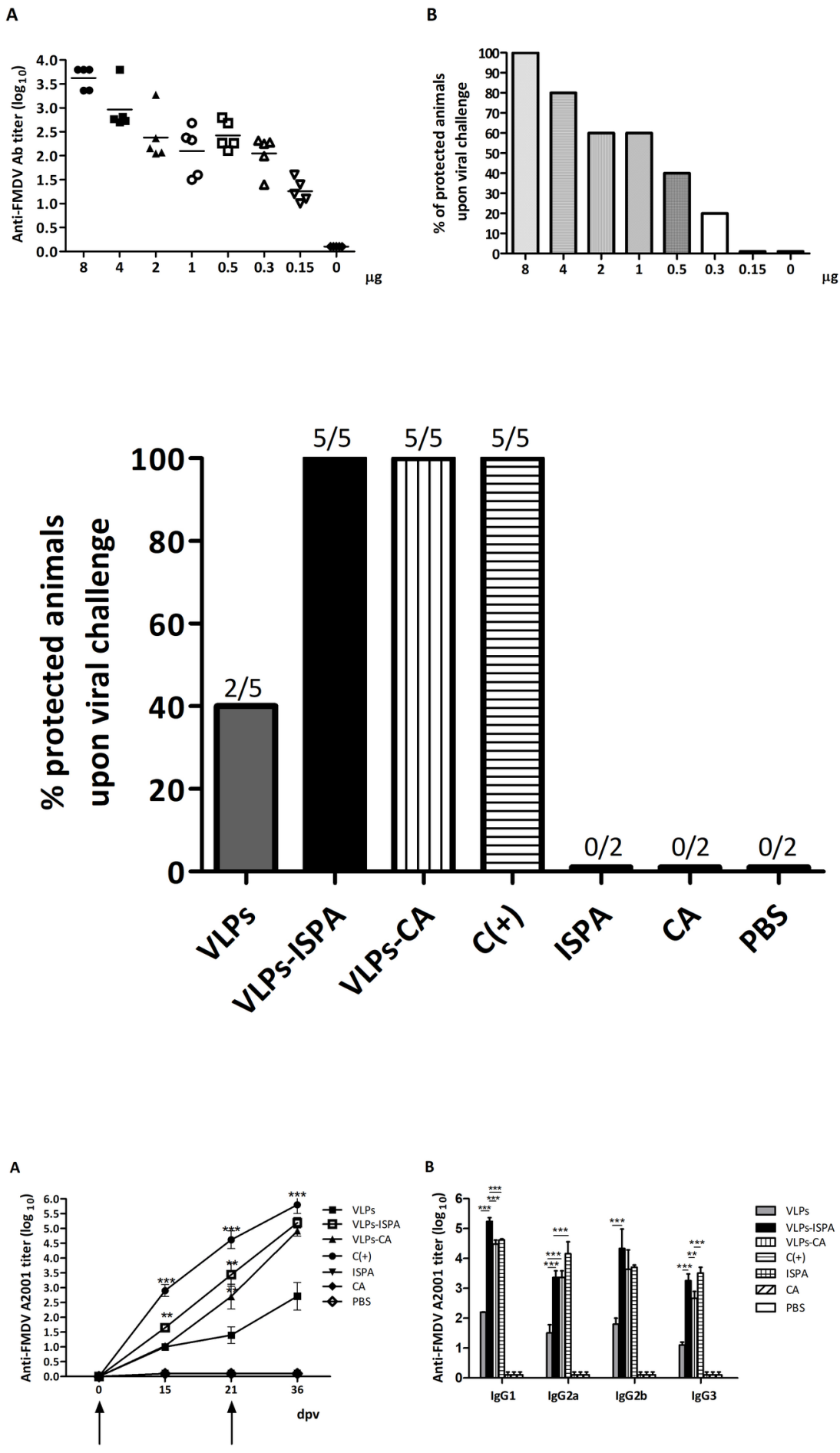

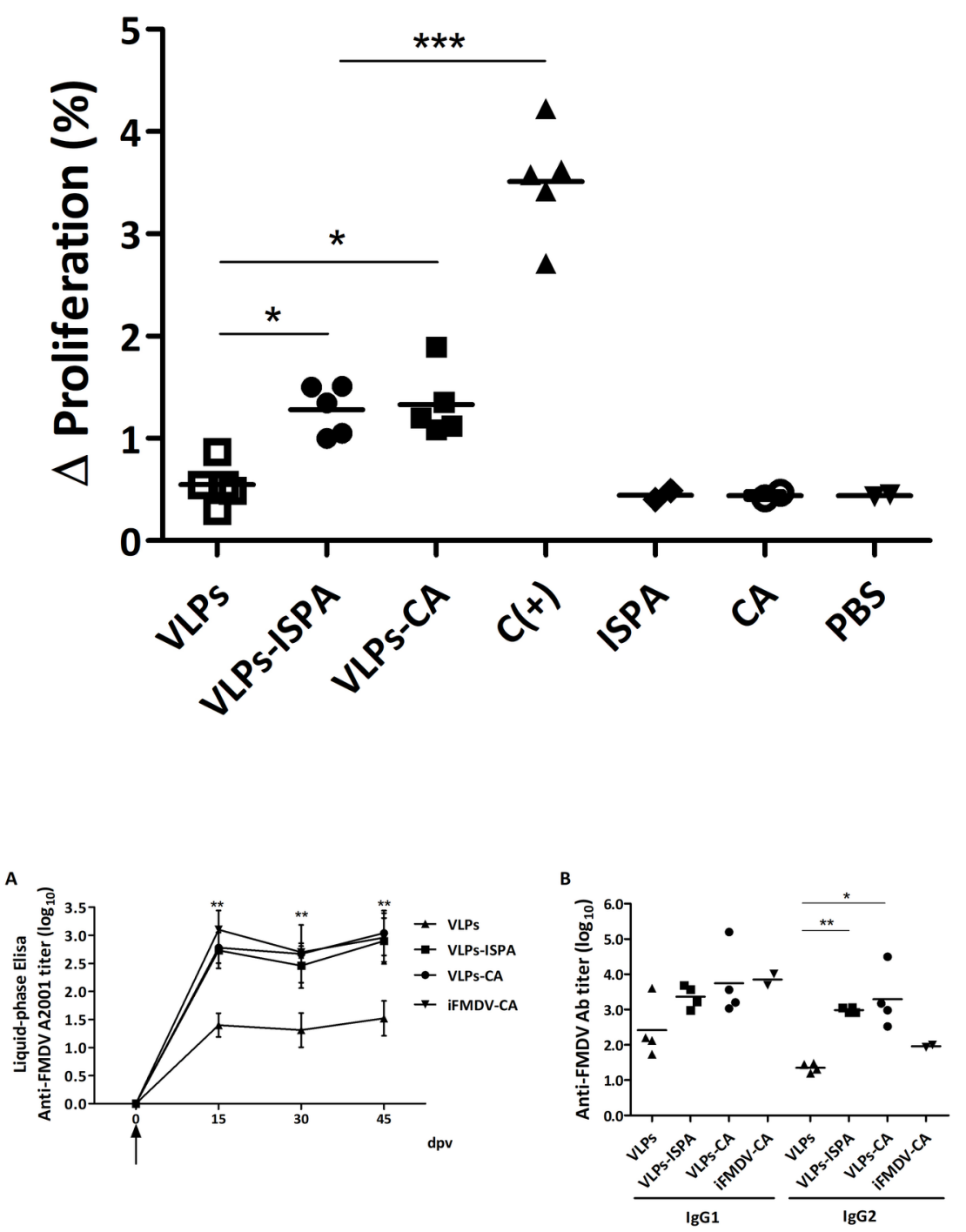


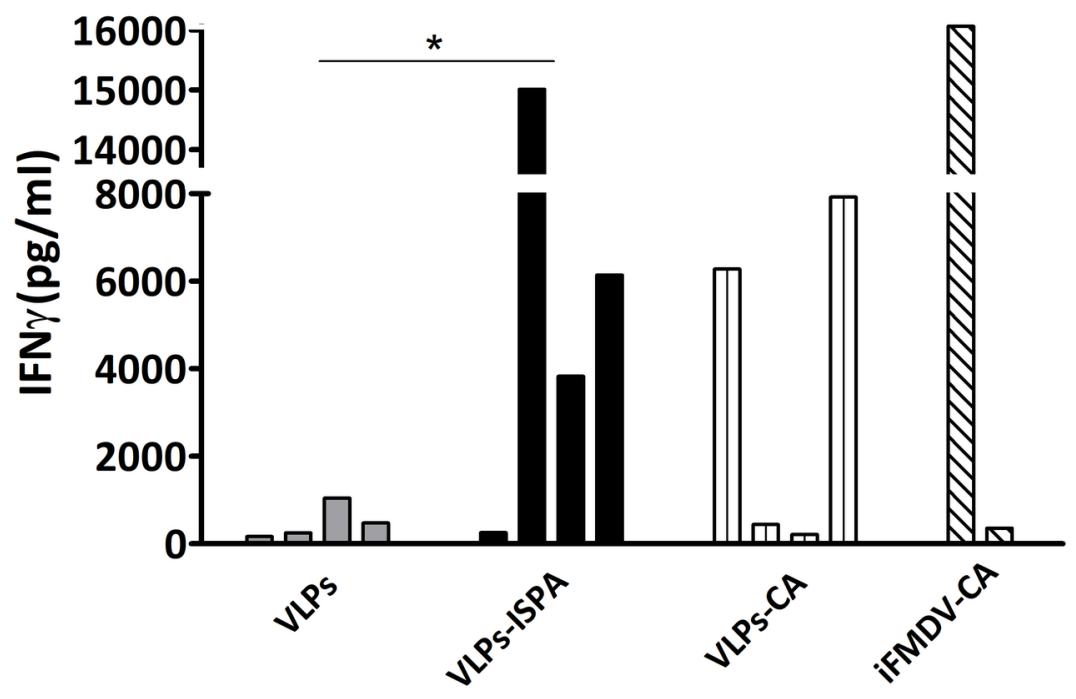

